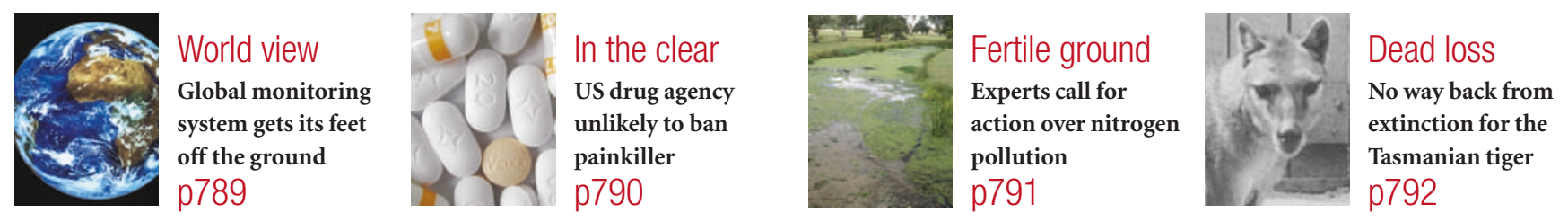

\title{
Tests in Tokyo reveal flaws in Vietnam's bird flu surveillance
}

\section{David Cyranoski, Tokyo}

Efforts to diagnose human cases of bird flu in Asia have been missing the mark, according to studies released last week. The findings have prompted calls for broader surveillance of the virus and a change in testing procedures.

Reanalysis of samples from Vietnamese patients with flu-like symptoms has revealed that some people originally declared free of bird flu actually did carry the avian virus H5N1. And another study has shown that some patients with symptoms other than those usually associated with flu were also suffering from $\mathrm{H} 5 \mathrm{~N} 1$.

The findings are worrying as they could mean that the virus has spread much more widely than was previously thought. This would, in theory, give the $\mathrm{H} 5 \mathrm{~N} 1$ strain a greater chance of mutating into a form that passes easily from person to person, potentially sparking a pandemic. Reassuringly, preliminary genetic analyses at the National Institute of Infectious Diseases (NIID) in Tokyo show that the virus has not mutated greatly since last year.

The recent findings could also lead experts to re-evaluate the severity of bird flu. The death rate for infected patients has so far been very high 10 of the 11 cases identified in Vietnam since December 2004 have died. But if many more cases are going unidentified, the mortality rate could be much lower.

Samples from the 11 recent cases of bird flu in Vietnam, plus those from some 90 suspected cases that tested negative for $\mathrm{H} 5 \mathrm{~N} 1$, were recently sent to the NIID for study. About a third of the samples have been examined so far and, of these, seven of the negative results have tested positive, says Phan Van Tu, head of the microbiology and immunology department at the Pasteur Institute in Ho Chi Minh City, Vietnam. Fresh tests in Vietnam last week confirmed four of these positive results.

Part of the discrepancy between labs

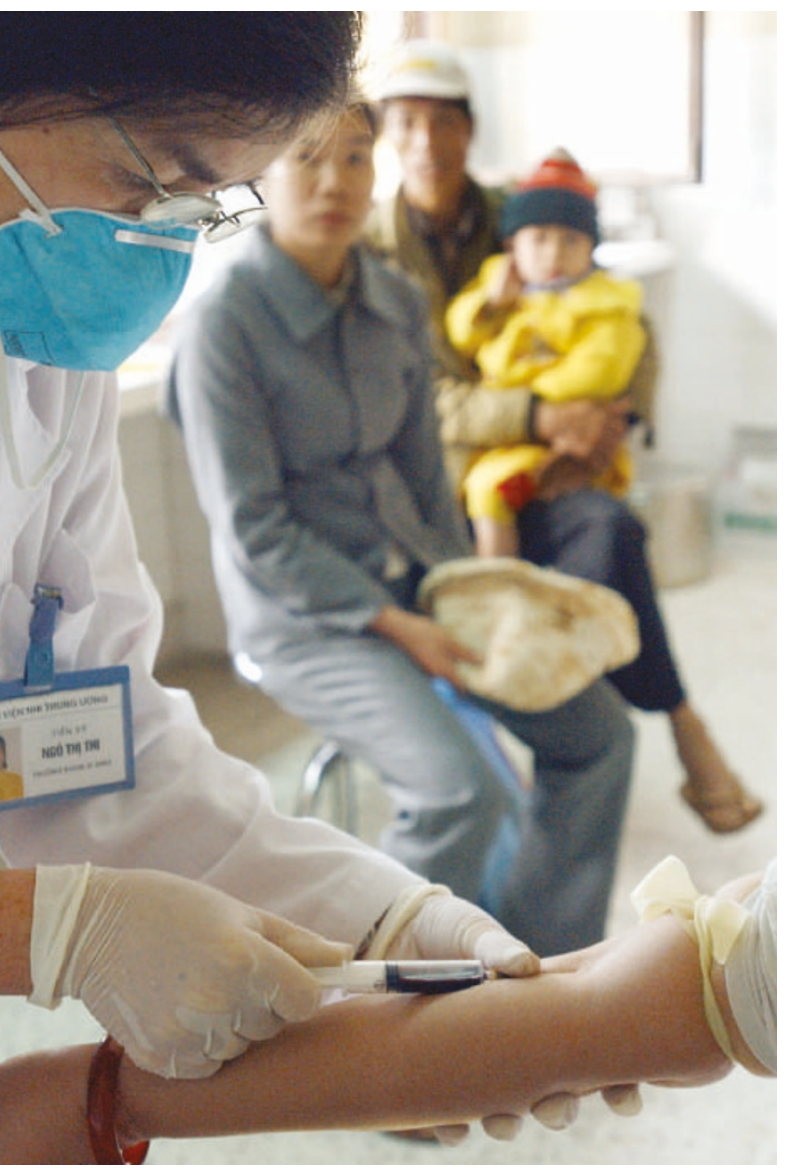

Diagnosis of bird flu in Vietnam has missed some human cases.

probable human-to-human transmission (K. Ungchusak et al. N. Engl. J. Med. 352, 333-340; 2005), but there are strong suspicions that clusters of disease within Asian families may have been transmitted through people rather than birds.

Concerns about $\mathrm{H} 5 \mathrm{~N} 1$ monitoring efforts have also been fuelled by a study showing that at least one case of encephalitis - a swelling of the brain - in Vietnam was caused by H5N1 (M.D. de Jong et al. N. Engl. J. Med.352, 686-691;2005).

Previously it was thought that the only clinical symptom of $\mathrm{H} 5 \mathrm{~N} 1$ was respiratory disease. As encephalitis is relatively common in Vietnam, this could mean that a broader approach to $\mathrm{H} 5 \mathrm{~N} 1$ monitoring is needed, says Menno de Jong, a virologist at the Hospital for Tropical Diseases in Ho Chi Minh City, who led the study. The known cases of H5N1 may be just the "tip of the iceberg", he says. Although he notes that in an analysis of a further 100 encephalitis patients, none was infected with bird flu.

Other cases could have slipped through the net if the patients had mild respiratory illness, de Jong says, as only severe cases have been studied. He and his group have now begun a one-year survey to look for

could be accounted for by problems with the original tests. "Some reagents were not mixed well and the results weren't clear," says Tu.

But for three cases the Pasteur researchers — with NIID researchers observing — reconfirmed their earlier negative diagnosis. This is worrying as it suggests that the Vietnamese test is not sensitive enough to detect all cases. Tu says that the institute now plans to switch to the more sensitive test used in Tokyo and will ensure better training for its technicians.

If many infections have been missed, "suspected cases of human-to-human transmission should be investigated again", says a member of a World Health Organization (WHO) collaborating laboratory. There has so far been only one documented case of
H5N1 among 1,600 children in Vietnam with mild symptoms.

In the meantime, many remain critical of current monitoring efforts. Henry Niman is the founder of Recombinomics, a company in Pittsburgh, Pennsylvania, that traces the molecular evolution of infectious agents. $\mathrm{He}$ claims that many cases of possible humanto-human transmission are not followed up properly. And a lack of widespread testing means that $\mathrm{H} 5 \mathrm{~N} 1$ could be to blame for other outbreaks, Niman says, such as a bout of apparent meningococcal blood poisoning that is ongoing in the Philippines.

There are no plans to test for $\mathrm{H} 5 \mathrm{~N} 1$ in the Philippines as yet. But the WHO is discussing how to broaden its surveillance of the virus. 